\title{
Titanium Ti-6Al-4V Alloy Milling by Applying Industrial Robots
}

\begin{abstract}
E. Grisol de Melo ${ }^{1}$, C. Mohnke ${ }^{2}$, J. Polte 3 , J. O. Gomes ${ }^{4}$, E. Uhlmann ${ }^{5}$
${ }^{1}$ Department of Mechanical Engineering, Aeronautics Institute of Technology (ITA), Marechal Eduardo Gomes 50, São José dos Campos 12228-900, Brazil; Fraunhofer Institute for Production Systems and Design Technology (IPK), Pascalstraße 8-9, Berlin, 10587, Germany (ever@ita.br) ORCID 0000-0001-5641-9407; ${ }^{2}$ Fraunhofer Institute for Production Systems and Design Technology (IPK), Pascalstraße 8-9, Berlin, 10587, Germany (christian.mohnke@ipk.fraunhofer.de); ${ }^{3}$ Fraunhofer Institute for Production Systems and Design Technology (IPK), Pascalstraße 8-9, Berlin, 10587, Germany (julian.polte@ipk.fraunhofer.de); ${ }^{4}$ Department of Mechanical Engineering, Aeronautics Institute of Technology (ITA), Marechal Eduardo Gomes 50, São José dos Campos 12228-900, Brazil (gomes@ita.br) ORCID 0000-0002-6004-799X; 5Fraunhofer Institute for Production Systems and Design Technology (IPK), Pascalstraße 8-9, Berlin, 10587, Germany (eckart.uhlmann@ipk.fraunhofer.de)
\end{abstract}

\begin{abstract}
Robotic machining is an alternative to manufacturing processes that combines the technologies of a high-performance machine tool with the flexibility of a 6-axis jointed arm robot. With their large working area, industrial robots are of particular interest for processing large-volume components and large structures, like aircraft components. An influencing variable, which is particularly relevant for milling processes with industrial robots are the cutting force $F$ and the resulting dimensional deviation D. Milling tests of titanium alloys were carried out with an industrial robot and the results compared with a conventional machine tool. Due to the low thermal conductivity and high chemical reactivity of the Ti-6Al-4V alloy, heat is generated and increases the temperature in the contact region of the cutting tool/work piece. That has an impact on the cutting tool wear and increases the cutting force $F$, and consequently, the dimensional deviation $D$ and the machined surface quality. The aim of the investigations is to find a suitable parameter selection and machining strategy for machining titanium alloys with minimal deviation $D$ and an appropriate surface finish.
\end{abstract}

Author Keywords. Titanium, Industrial Robot, Milling, Machining Process.

Type: Research Article

ठे Open Access $\square \overline{\text { Peer Reviewed }}$ @C) CC BY

\section{Introduction}

In the last decade, robotic processing has evolved from a basic research topic to a production technology for industrial use (Uhlmann, Wacinski, and Dethlefs 2012). The main reasons are technological progress and ongoing research (Uhlmann et al. 2013), which have led to an increase in accuracy. Robotic machining is an innovative production technology that combines the advantages of a highly accurate machine tool with the flexibility of a 6-axis jointed arm robot. Due to their relatively low investment costs $\mathrm{K}$ compared to machine tools, milling robot systems represent a cost-effective alternative. Continuous improvement of the industrial robots regarding stiffness $c$ and path accuracy AT results permanently in new industrial applications (Abele et al. 2013). Another advantage of inexpensive industrial robots is the relatively large usable workspace. The use of industrial robots is changing from assembly, logistics and handling tasks to applications in machining operations. 
Therefore, the use of industrial robots becomes increasingly promising for milling processes of aeronautical alloys. The main advantage of titanium alloys is the high strength to weight ratio Z. Titanium alloys are widely used for aircraft components. The large-scale structural components like wing ribs, spars, bulkheads, and frames are currently requiring machining processes with large machine tools (Asensio Dominguez et al. 2019). Milling processes with an industrial robot are an alternative (de Melo et al. 2020) for manufacturing large-scale components of titanium alloys. At the Fraunhofer IPK, test series were carried out with the aim of developing and establishing process principles and parameters for titanium Ti-6Al-4V alloy milling by applying industrial robots.

\section{Motivation}

Various disturbances occur during robot-guided milling. These disturbances have a considerable influence on the machining accuracy AP and the processing result. Due to the low stiffness $c$ of the industrial robots, high cutting forces $F$ can result in dimensional deviation $D$ and vibrations of the system. Vibrations during machining needs to be identified, classified, and then minimized or even eliminated when possible due to its negative effect on the tool life, machined surfaces (Asensio Dominguez et al. 2019) and the robot system. The milling process of titanium alloys is carried out at low cutting speeds $v_{c}$ and preferentially down cut milling to reduce cutting forces $F$. Low feed rates $\mathrm{v}_{f}$ can improve the surface roughness (Froes 2015). Titanium alloy has high chemical reactivity $y$ and low thermal conductivity $\lambda$ (Chanes de Souza 2019). Because of this, cutting parameters and material conditions result in a critical temperature of $\vartheta=700{ }^{\circ} \mathrm{C}$. The application of cutting fluid is required for cooling the work pieces, cutting tools, and removing chips from the interface (Chanes de Souza et al. 2020). And for machining processes featuring low cutting speeds vc, such as titanium alloys, the effect of process damping on process stability increases (Budak and Tunc 2010). Currently, there are no established processes and methods that can be used for machining titanium alloys with an industrial robot. For this reason, investigations for stable milling parameters can provide the basis for the industrial use of industrial robots for machining titanium alloys.

\section{Technological Investigations}

In the following section, the used machines, the test parameters, and the measuring methods are explained. The machining tests were carried out on a 6-axis jointed arm KUKA KR 60 HA from KUKA ROBOTER GMBH, Ausgburg, Germany, and for comparison on a machine tool DMU 50 from DMG MORI, Bielefeld, Germany. The industrial robot is equipped with the application module Milling ES350L 4P nominal power $P=8 \mathrm{~kW}$-from HSD SPA, Italy. The DMU 50 is equipped with a spindle with a nominal power of $P=16 \mathrm{~kW}$. The repeat accuracy of the KUKA $\mathrm{KR} 60 \mathrm{HA}$ is specified as AP $=0.05 \mathrm{~mm}$. The repeat accuracy of the DMU 50 is given as AP = $0.02 \mathrm{~mm}$ (Dostal et al. 2020).

Test plates made of titanium alloy are used for the milling tests. The material of the work pieces for milling test was Ti-6Al-4V alloy. The chemical composition and thermo mechanical properties are given in Table 1.

The cutting tool is a solid carbide milling cutter MTC/TPC TiAIN from HOFFMANN SE, München, Germany. The cutter has chip separators and is coated with TiAIN. The cutter diameter is $\phi=6 \mathrm{~mm}$. With number of teeth $z=5$, a helix angle of $45^{\circ}$ with unequal spacing is suitable for trochoidal performance cutting (TPC). The investigated cutting strategy was TPC and the cutting parameters are presented in the Table 2 . The tests were performed with a constant material removal ratio $\mathrm{MRR}=1070 \mathrm{~mm}^{3} / \mathrm{min}$. 


\begin{tabular}{cc}
\hline Material & Ti-6Al-4V \\
\hline Melting temperature $\vartheta\left[{ }^{\circ} \mathrm{C}\right]$ & 1667 \\
Thermal conductivity $\lambda[\mathrm{W} / \mathrm{mK}]$ & 6.7 \\
Tensile Strength $\mathrm{R}_{\mathrm{m}}[\mathrm{MPa}]$ & 905 \\
Modulus of elasticity $\mathrm{E}[\mathrm{GPa}]$ & 114 \\
Density $\rho\left[\mathrm{kg} / \mathrm{m}^{3}\right]$ & 4429 \\
Hardness $\mathrm{H}[-]$ & 320 \\
Yield strength $\mathrm{Re}[\mathrm{Mpa}]$ & 835 \\
\hline
\end{tabular}

Table 1: Work piece characteristics

According to Uhlmann et al. (2020), during the machining process and trochoidal operation, the cutting tool in-feed and out-feed the work piece every turn. During the in-feed the chip thickness $h$ is very low and increases with increasing wrap angle $\phi$. In out-feed occurs a rapid drop in the process forces $F$. This change in the cutting force F applied to the industrial robot, results in a deviation of the cutting tool path $D_{p}$ and consequently in a dimensional deviation D. This work evaluated the performance of the robot in machining of titanium alloy through the quality of dimensional deviation $D$.

\begin{tabular}{|c|cccc|}
\hline $\begin{array}{c}\text { Parameters } \\
\text { designation }\end{array}$ & A & B & C & D \\
\hline Eactor & $\begin{array}{c}\text { Feed per toot } \mathbf{f}_{\mathbf{z}} \\
{[\mathbf{m m}]}\end{array}$ & $\begin{array}{c}\text { Width of cut ae } \\
{[\mathbf{m m} / \mathbf{r e v}]}\end{array}$ & $\begin{array}{c}\text { Depth of cut } \mathbf{a p}_{\mathbf{p}} \\
{[\mathbf{m m}]}\end{array}$ & Methods \\
\hline Level & 0.090 & 0.36 & 0.5 & trochoidal \\
2 & 0.045 & 0.36 & 1.0 & trochoidal \\
3 & 0.036 & 0.36 & 1.25 & trochoidal \\
\hline
\end{tabular}

Table 2: Combinations list of factors and levels for the Titanium milling

Another way to determine performance quality of a milled work piece by the application of industrial robot is surface quality. According to Li and Liu (2013), the surface integrity and quality affected the life of products undergoing cyclic loads. In the investigation of Qin et al. (2014), the surface roughness of TiAIN-coated tool was $\mathrm{Ra}=0.3496 \mu \mathrm{m}$ in helical milling, and Zhang et al. (2020) obtained values of $\mathrm{Ra}=0.7 \mu \mathrm{m}$ for cutting depth $\mathrm{a}_{\mathrm{p}}=0.2 \mathrm{~mm}$ for conventional milling and $\mathrm{Ra}=0.18 \mu \mathrm{m}$ for rotary ultrasonic elliptical milling.

During the milling of titanium alloy occur high temperatures $\vartheta$. This high temperatures $\vartheta$ lead to higher cutting forces $F$, increased surface roughness, reduced tool life and inaccuracies in machined part dimension (Ravi, Gurusamy, and Mohanavel 2020). Due to the low stiffness c of the KUKA KR $60 \mathrm{HA}$, the cutting force F were only examined for machining with the industrial robot. The cutting forces $F$ should always be analyzed to avoid unstable cutting zones. During the milling investigations with the KUKA KR $60 \mathrm{HA}$, the resulting cutting forces $F$ and frequency $f$ response was analyzed by fast Fourier transform (FFT).

\section{Results}

\subsection{Surface roughness}

Figure 1 shows the comparison of the surface roughness of the trochoidal milling carried out on the industrial robot and the CNC machine tool with the influence of the cutting depth $\mathrm{ap}_{\mathrm{p}}$. 


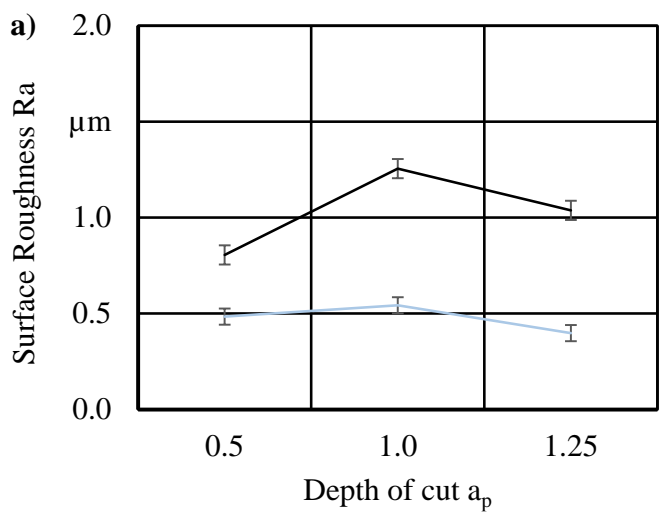

- Surface Roughness IR

Surface Roughness CNC

Measurement equipment

MAHR MarSurf PS10

Cutting parameters

$\mathrm{v}_{\mathrm{c}}=180 \mathrm{~m} / \mathrm{min}$

$\mathrm{a}_{\mathrm{e}}=0.5 \mathrm{~mm}$

Material

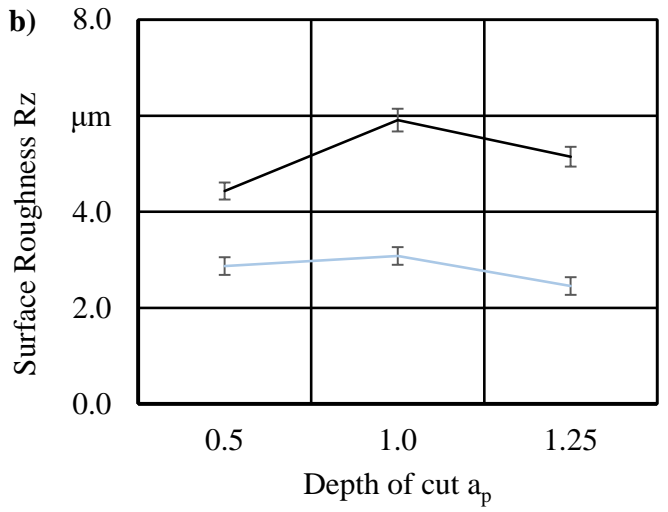

Ti-6Al-4V alloy

Cutting tools

Garant 203083

$\mathrm{z}=5$

$\emptyset=6 \mathrm{~mm}$

Figure 1: Comparative of Surface roughness - IR and CNC machine-tool,

(a) average surface roughness $(\mathrm{Ra})$ and $(\mathrm{b})$ maximal surface roughness ( $\mathrm{Rz}$ )

For the industrial robot, the cutting depth of $a_{p}=1.00 \mathrm{~mm}$ showed the highest values for arithmetical mean roughness $R a=1.26 \mu \mathrm{m}$ and mean roughness depth $\mathrm{Rz}=5.91 \mu \mathrm{m}$. These values were twice as high compared to the tests performed at the CNC machine tool with $\mathrm{Ra}=0.54 \mu \mathrm{m}$ and $\mathrm{Rz}=3.08 \mu \mathrm{m}$. The depth of cut $\mathrm{a}_{\mathrm{p}}=0.50 \mathrm{~mm}$ showed the lowest roughness $\mathrm{Ra}=0.81 \mu \mathrm{m}$ and $\mathrm{Rz}=4.43 \mu \mathrm{m}$, followed by depth of cut $\mathrm{a}_{\mathrm{p}}=1.25 \mathrm{~mm}$ with $\mathrm{Ra}=1.04 \mu \mathrm{m}$ and $\mathrm{Rz}=5.15 \mu \mathrm{m}$. For machining titanium alloy with a CNC machine tool, the best roughness with $\mathrm{Ra}=0.40 \mu \mathrm{m}$ and $\mathrm{Rz}=2.45 \mu \mathrm{m}$ was achieved with cutting depth $\mathrm{a}_{\mathrm{p}}=1.25 \mathrm{~mm}$. These results are mainly correlated to robot instability during trochoidal milling to depth of cut $a_{p}=1.00 \mathrm{~mm}$. Considering this investigation of milling titanium alloys using greater depths of cuts $a_{p}$, the results for surface roughness showed satisfactory qualities when compared with the results of the CNC machine tool. Besides the fact, the used machine-tool was an industrial robot, which presents lower stiffness compared to a conventional machinetool.

Figure 2 gives an overview of the quality of the milled paths for depths of cut $a_{p}=0.5 \mathrm{~mm}$, $a_{p}=1.0 \mathrm{~mm}$ and $a_{p}=1.25 \mathrm{~mm}$. In detail it can be seen, that the machining has not been deviated either in the in-feed of the cutting tool or in the out-feed of the cutting tool, Figure 2(a) and (b). The machining parameters evaluated confirm the feasibility of applying an industrial robot for milling titanium alloys and ensuring the final dimensions of the workpiece. 


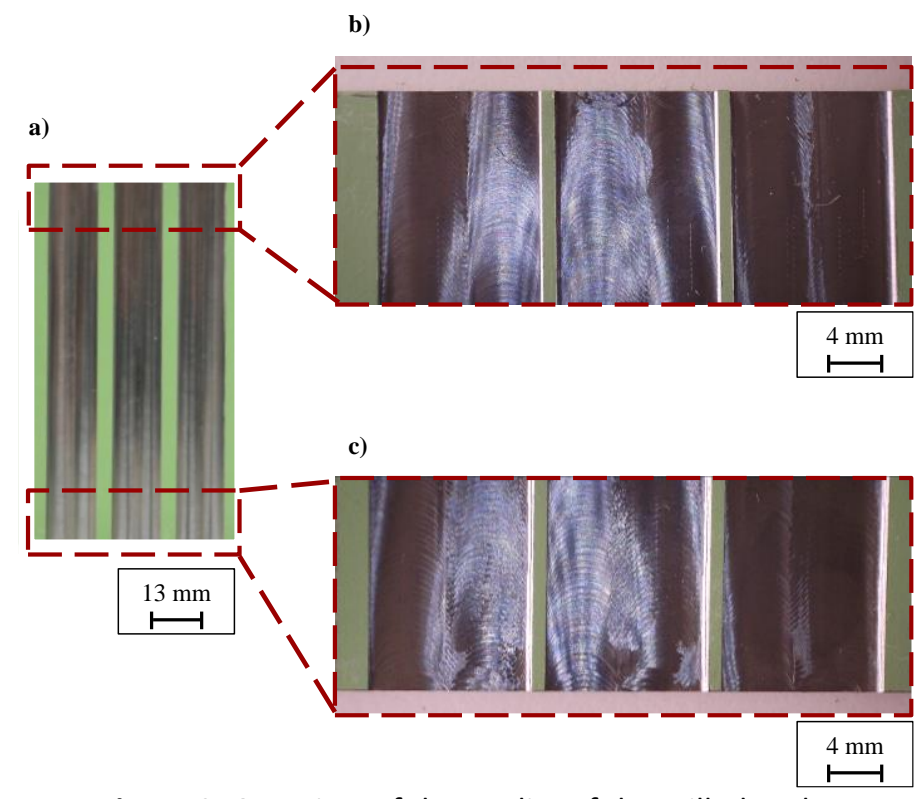

Figure 2: Overview of the quality of the milled paths

(a) Superior view; (b) cutting tool in-feed; (c) cutting tool out-feed

\subsection{Dimensional deviation}

Figure 3 shows the dimensional deviations $D$ from the slot width. For the KUKA KR 60 HA the depth of cut of $a_{p}=1.00 \mathrm{~mm}$ showed the largest dimensional deviation at $D=40 \mu \mathrm{m}$ during the output of the cutting tool from the work piece. In the conditions of depths of cut $a_{p}=0.5 \mathrm{~mm}$ and $a_{p}=1.25 \mathrm{~mm}$ the deviation was lower. The lowest deviation of $D=10 \mu \mathrm{m}$ is reached with $a_{p}=0.50 \mathrm{~mm}$ during the input of the cutting tool. This generated the hypothesis that if the engagement of the cutting tool can aid in stability of the cutting process. Since both conditions proved to be more stable. For all depth of cut ap the dimensional deviation $D$ for the machining tool is lower compared to the robot. The lowest value is reached with a depth of cut $a_{p}=0.5 \mathrm{~mm}$ and is $D=5 \mu \mathrm{m}$. The deviation is highest with $D=8 \mu \mathrm{m}$ with a depth of cut $a_{p}=1.25 \mathrm{~mm}$.

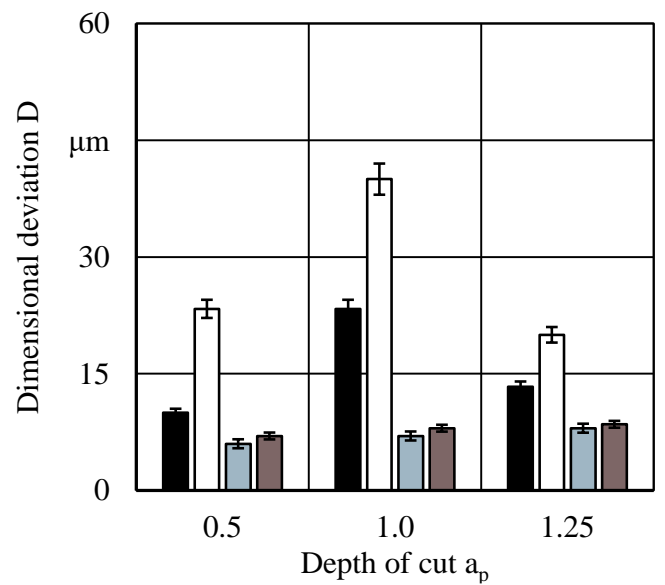

Trochoidal in IR

$\square$ Trochoidal out IR

$\square$ Trochoidal in $\mathrm{CNC}$

$\square$ Trochoidal out CNC

Measurement equipment

ROMER Absolute Arm $7325 \mathrm{Si}$

Material

Ti-6Al-4V alloy

Cutting tools

Garant 203083

$\mathrm{z}=5$

$\emptyset=6 \mathrm{~mm}$

Figure 3: Comparative of dimensional deviations D - IR and CNC machine-tool

\subsection{Cutting force}

Figure 4 shows the effect of cutting parameters on cutting force $F$ and torque moment $T$ for the KUKA KR $60 \mathrm{HA}$. The cutting force $\mathrm{F}$ and torque moment $\mathrm{T}$ increase as the cutting tools get to the maximum axial depth of cut $a_{p}$. For a depth of cut $a_{p}=0.5 \mathrm{~mm}$ the cutting force is $\mathrm{F}=80 \mathrm{~N}$. With higher depth of cut $a_{p}$ the cutting force rises from $\mathrm{F}=110 \mathrm{~N}$ up to $\mathrm{F}=130 \mathrm{~N}$. 
The lowest torque moment is $T=10 \mathrm{Nm}$ at a deep of cut of $a_{p}=0.5 \mathrm{~mm}$. The torque moment rises from $\mathrm{T}=14 \mathrm{Nm}$ up to $\mathrm{T}=15 \mathrm{Nm}$ with higher depth of cut $\mathrm{a}_{\mathrm{p}}$.
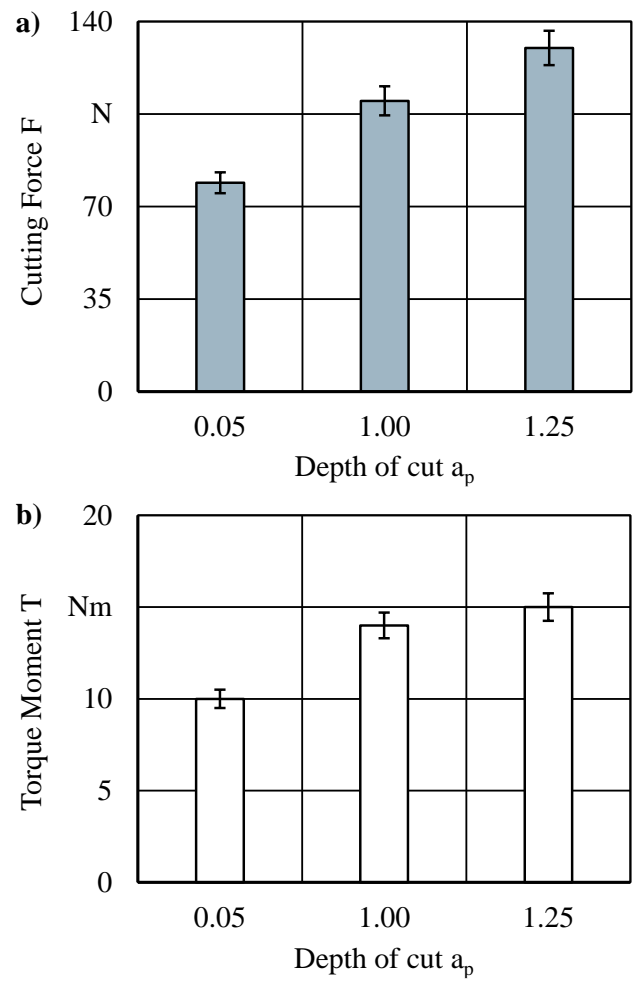

$\square$ Cutting Force

$\square$ Torque Moment

\section{Measurement equipment}

ATI INDUSTRIAL SERVICE

Force Torque Sensor SI-660-60

Cutting parameters

$\mathrm{v}_{\mathrm{c}}=180 \mathrm{~m} / \mathrm{min}$

$\mathrm{a}_{\mathrm{e}}=0.5 \mathrm{~mm}$

Material

Ti-6Al-4V alloy

\section{Cutting tools}

Garant 203083

$\mathrm{z}=5$

$\varnothing=6 \mathrm{~mm}$

Figure 4: Results of; (a) cutting force $F$ and (b) torque moment $T$

The cutting forces $F$ and torque moment $T$ show a cyclic nature, Figure 5 . The cutting force $F$ reaches maximum between the cutting start until the maximum radial depth $\mathrm{a}_{\mathrm{e}}$ was reached. The maximum $\mathrm{a}_{\mathrm{e}}$ is also seen as the moment $\mathrm{T}$ torque peak.
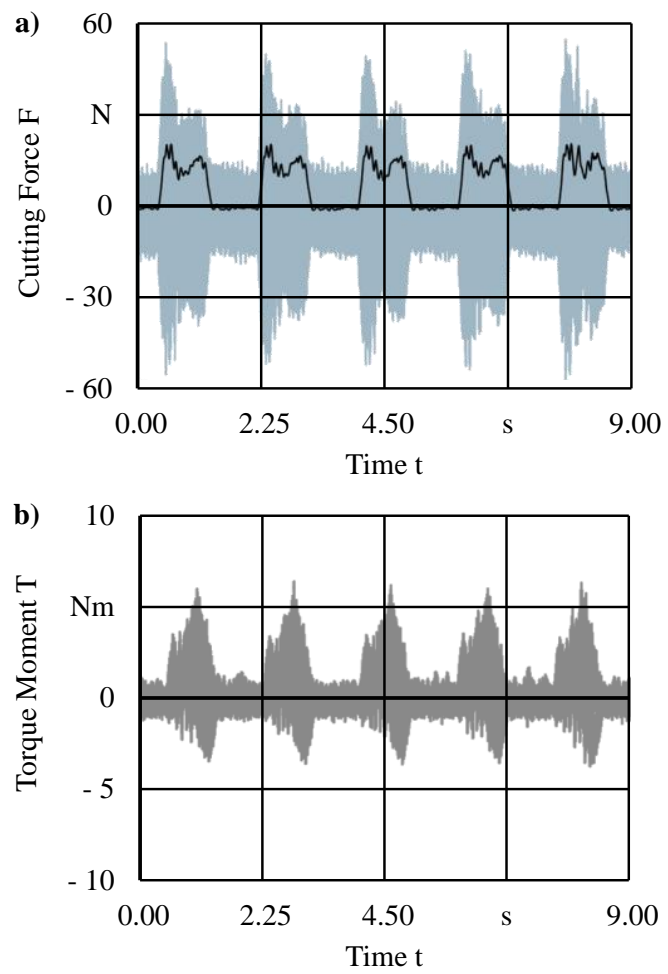

- Cutting Force F

(low pass filter)

Cutting Force F

— Torque Moment T

Measurement equipment

ATI INDUSTRIAL SERVICE

Force Torque Sensor SI-660-60

Cutting parameters

$\mathrm{v}_{\mathrm{c}}=180 \mathrm{~m} / \mathrm{min}$

$\mathrm{a}_{\mathrm{e}}=0.5 \mathrm{~mm}$

\section{Material}

Ti-6Al-4V alloy

\section{Cutting tools}

Garant 203083

$\mathrm{z}=5$

$\varnothing=6 \mathrm{~mm}$

Figure 5: Force F and Moment T signal over time t; (a) Cutting force F, (b) Torque moment $\mathrm{T}$ 
The Frequency spectrum of measured force signal (FFT) is shown in Figure 6. The chatter frequencies $f$ is higher for the depth of cut condition $a_{p}=1.00 \mathrm{~mm}$. The depth of cut $a_{p}=1.25 \mathrm{~mm}$ showed the highest stability for trochoidal milling by the application of the IR.

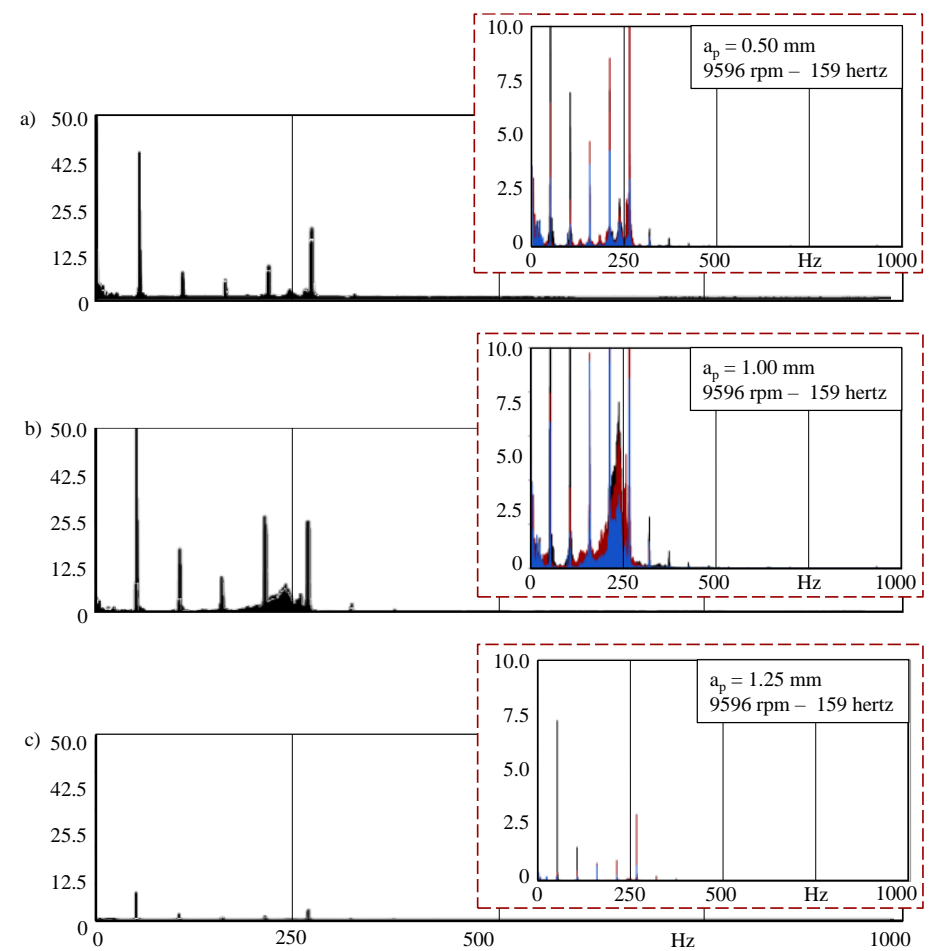

Figure 6: Frequency spectrum of measured force signal

Response Frequency - FFT; (a) ap = $0.50 \mathrm{~mm}$; (b) ap = $1.00 \mathrm{~mm}$; (c) ap = $1.25 \mathrm{~mm}$

The cutting tool engagement for the depth of cut $a_{p}=1.25 \mathrm{~mm}$ showed greater stability. Based on the results, a higher depth of cut $a_{p}$ is recommended for industrial robots. Even if the cutting force $F$ is $65 \%$ higher than the condition with depth of cut $a_{p}=0.05 \mathrm{~mm}$. In addition, the high instability with depth of cut $a_{p}=1.00 \mathrm{~mm}$ generated a greater dimensional deviation $D$, Figure 3 . This provides a hypothesis that the industrial robot's stability lobe will have different curves than the stability lobes provided by conventional machine tools.

\section{Summary}

This work showed the performance of IR compared with CNC machine-tool in Ti-6AI-4V alloy trochoidal milling. The industrial robot showed lower quality roughness results than CNC machine tools. With the DMU 50 it's possible to reach with cutting depth of ap $=1.25 \mathrm{~mm}$ surface roughness from $\mathrm{Ra}=0.40 \mu \mathrm{m}$ and $\mathrm{Rz}=2.45 \mu \mathrm{m}$. The KUKA KR $60 \mathrm{HA}$ achieved for a depth of cut ap $=1.25 \mathrm{~mm}$ a surface roughness of $\mathrm{Ra}=1.04 \mu \mathrm{m}$ and $\mathrm{Rz}=5.15 \mu \mathrm{m}$. This is more than twice as high as the values for the machine tool. Nevertheless, the results for the surface roughness with a robot are satisfactory. The low stiffness results for the cutting depth condition ap $=1.00 \mathrm{~mm}$ in high dimensional deviations $D$, cutting forces $F$ and surface roughness. By increasing the depth of cut to ap $=1.25 \mathrm{~mm}$ the quality of the machined surfaces increases too. The dimensional deviation $\mathrm{D}$ decreases by $50 \%$ and the surface roughness by $20 \%$ in comparison to the results with ap $=1.00 \mathrm{~mm}$. Compared to the machine tool, the values for the deviation $D$ are up to 9 times higher, depending on the depth of cut ap. The lowest deviation of $D=10 \mu \mathrm{m}$ for a robot is reached with ap $=0.50 \mathrm{~mm}$ during the input of the cutting tool. The lowest value for the DMU 50 is reached with a depth of cut ap $=0.5 \mathrm{~mm}$ and is $D=5 \mu \mathrm{m}$. 
It was shown that with adapted parameters and strategies it is possible to machine Ti 6Al 4V alloys with a robot. In comparison to the machine tool the results for dimensional deviation $D$ and surface roughness are higher for all depth of cut ap. But when comparing the cost of a robot and a machine tool, machining with an IR with adapted parameters can be useful in certain situations. The use of industrial robots in new processes is a tendency of companies to achieve the development of Industry 4.0. However, further research is necessary to understand the behavior of industrial robots in each type of application.

\section{References}

Abele, E., W. Polley, A. Ehm, and M. Troue. 2013. "Spanende bearbeitung mit industrierobotern: Thermische einflüsse auf die bearbeitungsgenauigkeit [Machining with industrial robots-thermal effects]". WT Werkstattstechnik 103, no. 9: 706-11.

Asensio Dominguez, L., A. Shokrani, J. M. Flynn, V. Dhokia, and S. T. Newman. 2019. "Application of multivariate statistical analysis for CNC milling of large Ti-6Al-4V components". Procedia Manufacturing 38: https://doi.org/10.1016/j.promfg.2020.01.111.

Budak, E., and L. T. Tunc. 2010. "Identification and modeling of process damping in turning and milling using a new approach". CIRP Annals - Manufacturing Technology 59, no. 1: 40308. https://doi.org/10.1016/j.cirp.2010.03.078.

Chanes de Souza, M. 2019. "Essay proposal for defining the requirements of vegetable-based oils for bio-lubricants on Al 7050-T7451 and Ti-6Al-4V alloys and natural biocides". PhD thesis, Mechanical Engineering and Aeronautics, Aeronautics Institute of Technology, Brazil.

Chanes de Souza, M., H. M. Wiesner, Y. Kuche, J. Polte, J. de Oliveira Gomes, and E. UhImann. 2020. "Influence of the fatty acid profile on the lubricating film formation in micro-milling process on 7050-T7451 aluminum alloy". International Journal of Advanced Manufacturing Technology 106, no. 1-2: 233-41. https://doi.org/10.1007/s00170-019-04625-x.

de Melo, E. G., T. B. Klein, S. Reinkober, J. D. O. Gomes, and E. Uhlmann. 2020. "Pocket milling of composite fibre-reinforced polymer using industrial robot". Procedia CIRP 85: 180-85. https://doi.org/10.1016/j.procir.2019.09.006.

Dostal, P., M. Sadilek, J. Dubsky, and P. Szkandera. 2020. "Accuracy of machine tools". MM Science Journal 2020: 3832-36. https://doi.org/10.17973/MMSJ.2020_03_2019132.

Froes, F. H., ed. 2015. Titanium - Physical metallurgy, processing and applications. Materials Park, Ohio: ASM International.

Li, Z., and Q. Liu. 2013. "Surface topography and roughness in hole-making by helical milling". International Journal of Advanced Manufacturing Technology 66, no. 9-12: 1415-25. https://doi.org/10.1007/s00170-012-4419-2.

Qin, X., X. Zhang, H. Li, B. Rong, D. Wang, H. Zhang, and G. Zuo. 2014. "Comparative analyses on tool wear in helical milling of Ti-6Al-4V using diamond-coated tool and TiAIN-coated tool". Journal of Advanced Mechanical Design Systems and Manufacturing 8, no. 1: JAMDSM0004. https://doi.org/10.1299/jamdsm.2014jamdsm0004.

Ravi, S., P. Gurusamy, and V. Mohanavel. 2020. "A review and assessment of effect of cutting fluids". Materials Today: Proceedings. https://doi.org/10.1016/j.matpr.2020.05.054.

Uhlmann, E., M. Wacinski, and A. Dethlefs. 2012. "Robotergeführte Kantenbearbeitung von Turbinenteilen". VDI Z-Integrierte Produktion 154, no. 5: 43. 
Uhlmann, E., F. Heitmüller, M. Manthei, and S. Reinkober. 2013. "Applicability of industrial robots for machining and repair processes". Procedia CIRP 11: 234-38. https://doi.org/10.1016/j.procir.2013.07.042.

Uhlmann, E., S. Reinkober, M. Hoffmann, and P. Käpernick. 2020. "Trochoid milling with industrial robots". Procedia Manufacturing 43: 447-54. https://doi.org/10.1016/j.promfg.2020.02.189.

Zhang, M., D. Zhang, D. Geng, J. Liu, Z. Shao, and X. Jiang. 2020. "Surface and sub-surface analysis of rotary ultrasonic elliptical end milling of Ti-6Al-4V". Materials and Design 191: 108658. https://doi.org/10.1016/j.matdes.2020.108658.

\section{Acknowledgments}

This work was supported by the Coordination for the Improvement of Higher Education Personnel - CAPES (grant number 88882.180844/2018-01); German Academic Exchange Service - DAAD (grant number 91744162); Institute for Production Systems and Design Technology - IPK; and Aeronautics Institute of Technology - ITA. 